\title{
Insights on Extent of Effectiveness, Trend, and Gap in Existing Frameworks for e-Procurement System
}

\author{
N. Madhusudan*, L. Manjunatha Rao** \\ * Department of Computer Science. City College, Bangalore, India \\ ** Department of Master of Computer Applications, Dr. Ambedkar Institute of Technology, Bangalore, India
}

\begin{tabular}{|c|c|}
\hline Article Info & ABSTRACT \\
\hline Article history: & With the advancement of technologies, the organization and business \\
\hline Received Sep14, 2015 & $\begin{array}{l}\text { applications are witnessed with the increasing trends to adopt cut edge } \\
\text { technologies to normalize their business process. However, this trend was not }\end{array}$ \\
\hline Revised Dec 15, 2015 & observed much on the e-Procurement system, where the existing users still \\
\hline Accepted Jan 5, 2016 & $\begin{array}{l}\text { place the purchase order using conventional web-based approach that cannot } \\
\text { address various ongoing challenges in eProcurement system. This paper }\end{array}$ \\
\hline Keyword: & $\begin{array}{l}\text { attempts to review the existing trends and challenges of web-based } \\
\text { eProcurement system and discusses that with the adoption of cloud }\end{array}$ \\
\hline Cloud & computing as present trend, such ongoing issues of eProcurement can be \\
\hline e-auction & $\begin{array}{l}\text { addressed. Ine paper discusses the effectiveness of the existing techniques } \\
\text { with interpretation of research gap. }\end{array}$ \\
\hline e-invoicing & \\
\hline e-Procurement & \\
\hline Supply Chain Management & $\begin{array}{r}\text { Copyright (C) } 2016 \text { Institute of Advanced Engineering and Science. } \\
\text { All rights reserved. }\end{array}$ \\
\hline \multicolumn{2}{|l|}{ Corresponding Author: } \\
\hline \multicolumn{2}{|l|}{ N. Madhusudan } \\
\hline \multicolumn{2}{|c|}{ Associate Professor: Dept of Computer Science. } \\
\hline \multicolumn{2}{|c|}{ City College } \\
\hline \multicolumn{2}{|c|}{ Bangalore, India } \\
\hline \multicolumn{2}{|c|}{ E-Mail: nmadhusudanresearch@gmail.com } \\
\hline
\end{tabular}

\section{INTRODUCTION}

E-Procurement is the method applied by the user to purchase the products or the services online. However, technically speaking, e-procurement is a typical case of business to consumer or government purchase as well as various forms of supplies, services, and work using internet and other modern technological devices as the medium of purchase [1] [2]. However, it is not that easy by the name, which shows that it is all about online purchase. Basically, e-procurement works by integration of various types of components e.g. purchase order integration, shipment management, e-tendering, status updates of active order, e-auctioning, and vendor management [4] [5]. However, the e-procurement system is designed on various distinct operation i.e. spend analysis, supplier assessment, supplier identification, sourcing, contract management, procurement, order fulfillment, and invoicing [5] [6]. The key features of any standard eprocurement model are Purchase orders, Requisitioning, Budgeting, Approval management, Quotation Management, Invoicing [7] [8].

The prime motive of this manuscript is to explore about the existing e-procurement system, discuss its issues, and highlights how cloud computing assists in solving the issues of conventional e-procurement system. The paper also discusses about the significant research gap in the existing system and highlights the brief of future study. Section 1 discusses about the Introduction to the domain of the study with brief highlights about the background and problem identification. Section 2 discusses about research methodology and Research and discussion has been discusses in Section 3and Section 4 makes some concluding remarks. 


\subsection{Background}

This section discusses about the background of the study highlighting the prior research attempts towards designing e-Procurement system till date. Chen et al. [9] has presented a study for implementing a conventional e-procurement system taking the case study of shipping industry. The system was designed using Java. However, the limitation of the study is it was tested using quantitative analysis without much empirical technique, that doesn't prove much reliability or applicability of this system. Ho et al. [10] carried out the study to investigate the influence of e-procurement system on firm's performance using hypothetical modelling and not with computational model. Hernandez et al. [11] have presented a study on supply chain management emphasizing on the SOA model to enhance the performance. One of the significant studies towards e-Procurement was carried out by Fong and Yan [12]. The design of the model is experimented in real-time considering the specifc case study of e-tendering system. Unfortunately, the outcome of the study is not accompanied by any significant benchmarking. Subramaniam and Shaw [13] have presented a study towards web-based e-procurement system to leverage the e-commerce system. The limitation of the study is absence of discussion of computational techniques or an efficient implementation procedure to design the web-based e-procurement system. Gardenal et al. [14] have presented a framework for e-procurement in public sector using qualitative approach. Bikshapathi and Raghuveer [15] have presented a design of eProcurement system considering the case study of Andhra Pradesh. Azar et al. [16] have adopted the UML approacxch to address the ongoing challenges of e-Procurement system. From software engineering viewpoint, the study has presented a flexible design pattern of using conventional e-procurement system. Trkman and McCormack [17] have presented a paper discussing about the advantages and threats of eProcurement system. This is significantly a good technical manuscript compared to all the above manuscripted explored. The authors have vividly described the methodology and evaluation procedure for better clarity in implementation of the study. Another better quality of technical study towards eprocurement was carried out by Matt et al. [18], where the authors have introduced a technique for supporting higher degree of flexibility in design phase. The author has used open source tool to design the modules involved in the study. However, the study has lesser extent of discussion of result and validation of its outcomes. Sato and Asahi [19] have carried out a study to interpret a framework that can map the buying behaviour of the user using mathematical model on the online dataset. The outcomes were validated using ROC (Receiver Operation Charecteristic) curve. Subramaniam et al. [20] have used XML based approach as an annotation scheme that can be adopted for dynamic database management in e-commerce application. However, the outcome lacks the implications of design pattern as well as software engineering.

\subsection{The Problem}

The problem identifications of usage of conventional e-Procurement system are as follows:

- At present, the purchaser is not provided with any access to the e-Procurement tools adopted by the firm.

- Attaining synchronization and streamlining the entire e-procurement system with the existing system is quite time consuming for the employees working in process management wih less technical skills.

- Lack of connectivity of participation of the suppliers to the organization-based e-procurement tools leads to tedius manual search, identification, and assessing an effective suppliers.

- $\quad$ The existing e-Procurement application doesn't provide much user friendly experience to its purchasers as well as other stake holders.

- The conventional system of e-Procurement calls for customer based design depending upon the existing requirement of an organization without much focus on flexibility and reusability of the software patterns.

- Existing web-based e-Procurement system also doesn't focus on standard cryptographic technique and is not definitely resilient againt various sorts of internet-based attack.

- Majority of the existing research toward conventional e-Procurement system is based on theoretical study where the implications on real-time can be hardly be evaluated.

\subsection{The Proposed System}

As the applications of the e-procurement posses various sensitive information, hence, it is essential to know the ranges of requisite factor to ensure an efficient design of e-procurement framework. Some of the essential requirements of the e-procurement framework are as follows [21]:

- It is essential that there must a switching of the entire business process from the original purchasing method to standard e-procurement.

- It is important to ensure an optimal security using PKI (Public-Key Infrastructure) based encryption, asymmetric key or symmetric key based on the targeted applications.

- The communication channel for the bidder should be provided with SSL (Secure Socket Layer) to ensure safer bids. 
- The system should retain enough transparency along with security for the tending operation in eprocurement system.

- There should be usage of the standard legally accepted template to assist the user for better purchase experience and adherence to the government standards.

- All the bids taking place should be authenticated by PKI techniques or performing encryption. Similarly, robust and fail-proof decryption techniques could be used to further authenticate the encrypted bid.

- The cumulative software and hardware to be used should be highly relevant to the applications of eprocurement system.

- There should be a mandatory provision of incorporating firewalls and third party security systems to secure the communication channel between the user and the service provider. It is also important that such security patches should be regularly updated both in online and offline mode.

- The operating system of the user should be safeguarded against any illegitimate or malicious programmes that could act as potential threat to the e-procurement framework.

- There should be provision of regular audit for the applications running on the top of e-procurement system.

- It is essential to specify the type of key (whether public or private) by the PKI management tool for the purpose of validating the ongoing transactions or bids.

- It is also critical to provide password invisibility for any technical members on the background (e.g. administrator) to ensure optimal privacy and confidentiality of the transactions.

- There should not be any system in e-procurement that facilitates forgetting of the user's password. As in that case, administrator might misuse the resetting of the password option. In such cases, the generated new password should be signed digitally only on the request of the user.

\section{RESEARCH METHODOLOGY}

According to the standard specification, the quality of the e-procurement model should posses following layers e.g. i) data layer, ii) application layer, iii) infrastructure layer, and iv) process layer. According to the General Financial Rules (GFR) of IT Act-2005 [22], it is necessary that e-procurement system should work only in these 4 layers for carrying out its necessary operation as standards. Pictorial description of the standard framework of e-procurement is shown in Figure 1.

- Data Layer: This layer is required to ensure the storage of the data that are being transacted or generated using e-procurement system. This layer is also characterized by inclusion of security audits for each transacted data and validation of the cryptographic protocols to be used for encryption.

- Application Layer: This layer consists of both high level and low level design of the e-procurement framework to ensure excercising the best operational practices. Various tools are used to review the code of application layer e.g. Application Call Graph, Rule violation, memory leaks, dead codes etc. The conformance of application layer is done using functional testing towards data validation.

- Infrastructure Layer: The infrastructer layer of e-procurement is equipped with numerous components e.g. load balancing, server, security systems (firewalls), etc. Conformance of design of infrastructure layer is done by using penetration testing (decrypting password, fingerprinting, intrusion scanning etc) and performance testing (memory usage, CPU saturation statistics etc.).

- Process Layer: The conformance of the process layer is done by ISO 27001 standards that is mainly designed to ascertained secure SLA adherence. All the process being formulated in this layer is subjected for optimal secury and configured by hierarchical access policy.

Apart from the inclusion of the above layer, it is important that there should be a specific certification policy of the adopted e-procurement application to ensure better conformance of the international standards and highly flexible for any future amendments to be made to map with the business process. There has been some research work in order to explore better frameworks in e-procurement in last decade. Singh and Thomson [23] have considered the case study of Australian e-procurement framework. The authors have proposed a model that is built up using buyer module, marketplace module, setting up relationship module, and seller module. Similar case study was also selected by Vaidya et al. [24] using balanced scoreboard. Parida [25] have presented a framework to investigate its possible impact on performance of a firm. The core components of the model are efficiency, effectiveness, dematerization, transparency, and competitiveness. The authors have adopted qualitative approach to build the framework that was analyzed using descriptive statistics. Bof and Previtali [26] have presented various national frameworks for adoption of e-procurement model to enhancing the purchasing experience considering the case study of public entities in Italy. The study has been framed using illustrative technique of methodology. Sharma and Vaisla [27] have presented a model of e-governance framework taking the case study of 
Uttarakhand in India. The model is quite theoretical and provides extremely less evidence of its operationality and essentials of software engineering being done on it.

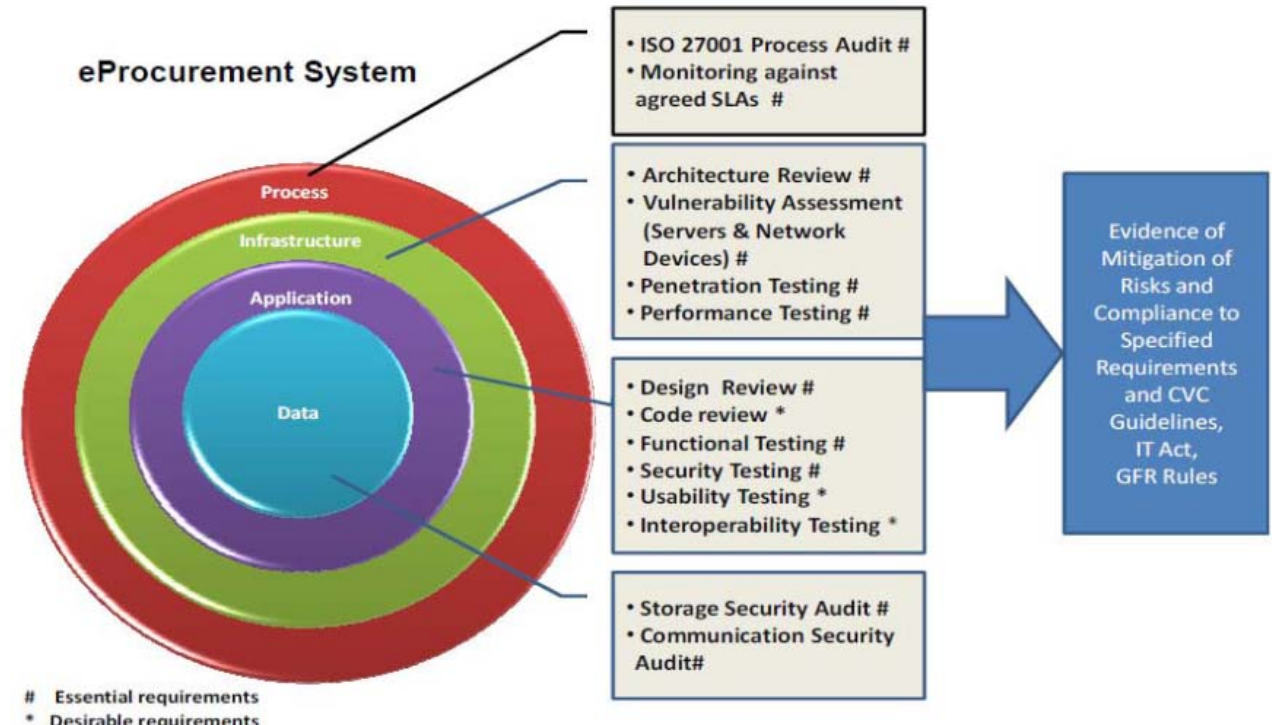

Figure 1. Standard Framework of E-Procurement [21]

Eadie et al. [28] have introduced a model responsible for desigining compatibility maturity model of e-procurement considering the case study UK construction sectors. The study has also identified around 32 factors which have acted as impediments towards usage of e-procurement system in construction sector in UK. However, the limitation of the presented framework is i) no benchmarking or standardization of the framework making it difficult to understand the effectiveness, ii) lack of inclusion of security standards, and iii) no discussion on conformance of this model with the standard framework of e-procurement.

\subsection{Challenges in E-Procurement}

In order to maintain a synchronized pace with the advanced technological adoption by various firms and users, it is necessary to identify the issues and impediments towards growth or enhancement of performance in e-procurement system. As discussed in prior section that e-procurement system must adhere to the optimal security standards to ensure privacy and confidentiality of the transactions. One important need is to use the time stamping technique of all events (major or minor transactions) in order to have better retrieval and analysis of the purchase history. It is also quite essential that e-procurement system must also adhere to the general financial standards. Primarily the adoption of e-procurement system mainly targets to minimize the cost of purchasing and ensure highly standard process for placing online purchase. Other advantages are minized discretion in the cycle of procurement with minimized cost of administrative task further enhancing the productivity. However, if the applications of e-government is so well structure, than it would have been much in advanced stage and already be used in existing system. But in reality, there are various complexities associated with the adoption of e-procurement system among the common users or generalized firms, who don't posses much technical inputs about the flexibility as well as complexities connected to e-procurement. Still adoption of conventional procurement system is exercised by majority of the vendors or the firms. However, assuming that there are some group of enthusiastic user who have already adopted e-procurement system, there are various sorts of challenges as i) lack of knowledge about the effectiveness of e-procurement system, ii) majority of the suppliers are not ready to integrate their process with it, iii) normally the approach, techniques, and tools used to perform system integration is highly incompatible and not much interoperable in existing system, and finally, iv) its the staff or the members who are not highly skilled to operation complex e-procurement system in existing era. Apart from these issues, existing e-procurement applications also suffers from other critical issues e.g.

- Less capability to perform integration of existing e-procurement applications with upcoming ERP systems.

- It is quite difficult to provide online support for the suppliers and various other types of vendors. 
- Conventional e-procurement system is characterized by complex user interface, which is quite challenging to operate effectively.

\subsection{Upcoming Trend of E-Procurement}

It has been witnessed that majority of the business process are moving on the cloud and so is eprocurement system. Cloud computing has introduced a new path for enhancing the business operation in most cost-effective way. By adopting the concept of virtualization and various forms of services (SaaS, Iaas, Paas, etc), cloud computing offers better licensing of the software targeting to solve any complex problem in business applications. From the expenditure viewpoint too, if the existing e-procurement system moves on the cloud, both users and vendors can save money and time that is spend on existing conventional eprocurement system. Some of the existing e-procurement systems over clouds are Coupa Procurement, eBid eXchange, Tofino, Procurify, BonFire, BidSync eProcurement, BuyerQuest eProcurement, P3Expditor, iSourcing Solution, Ivalua Buyer, Ariba Spend Management Suit, Bupros Spend Management, Zycus Procurement, eSourcing, etc [29]. The prime reason for increasing trend of switching over to cloud eprocurement system as due to following factors viz. i) Capability to support multi-tenant, ii) Synchronous with workflow, iii) User-Friendlines, Flexibility of Configuration, Ease in Integration. Wang [30] have emphasized on problem of using qualitative approach. The outcome of the study was found to posses seamless procurement in public cloud. However, it did not discuss vividly and there was no benchmarking. Kiroski [31] have focused on the problem on e-invoicing using multi-tenant cloud using IaaS. The outcome of the study was found to posses Enhance scalability. The study has introduced a completely hypothetical model with no discussion of results vividly. Ojha [32] have focused on problem associated with eprocurement in Karnataka. Grilo [33] have focused on the problem of dynamicity of ICT using model-driven and service-oriented architecture. The outcome of the study was found to posses capability to process unstructured data. However, it lacks security and outcomes not discussed vividly. Magnusson [34] have emphasized on the problem of cost of deployment using theoretical model. The outcome of the study was found to effective analysis cost of switching to cloud. The scope of applicability is very less in real-time. Shalle [35] have introduced a study towards investigating Procurement performance using qualitative study. The outcome of the study was found to posses efficient service and procurement automation. The outcome also posses less evidence to show scope of applicability in real-time. Mencia [36] have presented a technique to evaluate e-procurement data using datamining. The outcome has accomplished $32 \%$ accuracy of analysis with no benchmarking. The experiment was carried out on dataset and not real-time data. Maniranjetha [37] have focused on resource procurement in cloud using mechanism design. The outcome of the study shows automation of procurement model done with no benchmarking. Naldi [38] have focused on problem associated with prediction of uncertainty using Geometric Brownian motion model. The outcome of the study shows to supports decision making with no benchmarking. Zhang [39] have presented a model of e-Auction using scheduling \& allocation of process. The study outcome shows an effective service differentiation. However, it doesn't mitigate integration problem.

\section{RESEARCH \& DISCUSSION}

This section discusses about the significant research gap that is extracted after reviewing the existing literatures towards e-procurement system. The prominent tradeoff found on the existing research attempts till dates are:

- Insufficient Technical Research: It was seen that are more than 39 papers pertaining to technical implementation of e-Procurement system and only 10 papers on cloud-based e-Procurement system. Moreover majority of the existing work have adopted qualitative methodologies where data were captured using questionnaires. Technical implementation of cloud framework is quite less focused in eProcurement system till date. Although, there are more number of whitepapers available on internetbased resources, but extremely less manuscript is found to showcase the problems pertaining to cloud based framework. Hence, it can be said that there is a need to continue investigating on problems associated with cloud based e-procurement system with evolution of various models.

- Less focus on Genuine Problems: At present, it was seen that integration of complex system, dynamicity of process, and user friendly interface are some of the significant problems. Majority of the work till date are found not to emphasize on these problems as there are no standard manuscript to claim so. Software modelling of the original research problem in e-Procurement system with adoption of experimental methodologies are not found much in existing work. Moreover, majority of the models presented are of hypothetical type, which doesn't prove the way it solves the original problems in cloud based e-Procurement system. 
- Less Focus on Validation Model: Although there are standards fixed for design and development of eProcurement system, but till date none of the existing work is found to adhere to the standard framework specifications. Another interesting observation is there is less work being done towards adopting computational model to design algorithm or mathematical model tested on real-time environment. Hypithetical models can be tested if their algorithms and standards are specified in the existing work, which is completely missing in literatures. Design of algorithms is always tested in space and time complexity, which was never being adopted by any researcher presenting their techniques of cloud-based e-procurement system.

\section{CONCLUSION}

With the increasing adoption of the cloud computing on various enterprise applications in modern era, e-procurement system is also not left out. This paper has attempted to showcase that e-procurement is not merely an application to make online purchases, but it has many other contributory features. While adopting e-procurement system assists on online placement of purchase order, it also assists the stakeholder to monitor as well as control their buying behaviour in terms of expenditure. This paper has initially discussed about the background of the e-procurement system stating the most essential components responsible to successfully operate on e-Procurement system and slowly the discussion was inclined towards briefing the problems in this area. The next phase of discussion was towards understanding the crtitical requirements of eprocurement system with exclusive highlights on the standards of the eprocurement system. The discussion shows that if any researchers are attempting to design eprocurement system, it should abide by the globally acclaimed standards. The consecutive phase of discussion was towards understanding the potential challenges of existing and conventional web-based e-procurement system. The next phase of the paper has discussed the evolution of cloud computing where it was stated various positive justification of how the adoption of cloud computing could possible solve the ongoing issues of conventional eprocurement system. The discussion was also followed by existing studies towards adoption of cloud on eProcurement system where some ground truth has been explored. It was seen that till date there are no work which claims about benchmarked outcomes, or supported by computational model to testify the effectiveness of the presented work till date. Evidence of these findings are summarized in research gap, which is meant to put forward a true picture of the existing system. The outcomes cumulatively suggest that there is critical need to evolve up with a computational model that can efficiently handle the ongoing problems found ignored in existing literatures. Our future work will be definitely toward evolving up with a computational model, which will be designed based on empirical and experimental methodologies and we will also plan to perform benchmarking with an existing model to showcase the effectiveness of our upcoming model.

\section{REFERENCES}

[1] O. Pablos, Patricia, E-Procurement Management for Successful Electronic Government Systems, IGI Global, Business \& Economics, 2012.

[2] Bwalya, K. Joseph, Technology Development and Platform Enhancements for Successful Global E-Government Design, IGI Global, Political Science, 2013.

[3] C.S.R. Prabhu, E-Governance: Concepts And Case Studies, PHI Learning Pvt. Ltd., Business \& Economics, 2013.

[4] K. Roebuck, Electronic commerce: High-impact Strategies - What You Need to Know: Definitions, Adoptions, Impact, Benefits, Maturity, Vendors, Emereo Publishing, Computers, 2012.

[5] C. Cunha, M. Manuela, E-Business Managerial Aspects, Solutions and Case Studies, IGI Global, Business \& Economics, 2010.

[6] Leenders, Leenders, A. Flynn, P.F. Johnson, Purchasing \& Supply Mgmt, Tata McGraw-Hill Education, Industrial procurement, 2010.

[7] R.K. Sinha, Financial Management and Legal Affairs for Non-Profit Organisations In India, Lulu Press, Inc, Business \& Economics, 2014.

[8] P. Gopalakrishnan, Haleem, Handbook Of Materials Management, PHI Learning Pvt. Ltd., Business \& Economics, 2015.

[9] Y.C. Chen, C.N. Chu, H.M. Sun, R.S. Chen, Y.H. Yang, "Design and Implement of a Web-based E-Procurement System Platform for Shipping Line, WSEAS Transactions on Computers, Volume 13, 2014.

[10] C.F. Ho, Y.M. Tai, W.H. Wu, J.J. Jou, "Exploring the impacts of web-based E-procurement on organizational performance", International Journal of Logistics Research and Applications: A Leading Journal of Supply Chain Management, Vol.7, Iss.3, 2014.

[11] G.A. Hernandez, A.A.A. Laserre, G.C. Robles, and C.S. Ramirez, "Improving E-Procurement in Supply Chain Through Web Technologies: The HYDRA Approach”, IntechOpen, 2011.

[12] S. Fong, Z. Yan, “Design of a Web-based Tendering System for e-Government Procurement”, ACM- Proceedings of the 3rd international conference on Theory and practice of electronic governance, Pages 321-328, 2009. 
[13] C. Subramaniam and M.J. Shaw, "A Study on the Value and Impact of B2B E-commerce: The Case of Web-based Procurement”, ACM- Journal International Journal of Electronic Commerce archive, Vol.6, Iss.4, No.4, pp.19-40, 2002.

[14] F. Gardenal, A.D. Angelo, and V. Manzo, "A model to measure e-procurement impacts on organizational performance”, Journal of Public Procurement, Vol. 13 Iss.2, pp.215, 2013.

[15] K. Bikshapathi, P. Raghuveer, "Implementation of e-procurement in the Government of Andhra Pradesh: A Case Study”, Report taken from World bank, 2006.

[16] S.A. Azar, B. Zarei, H. Soltanpanah, and S. Alaniazar, "E-Procurement System Challenges And Design: An UML Approach”, Australian Journal of Basic and Applied Sciences, vol.5, Iss.12, pp.1418-1427, 2011.

[17] P. Trkman and K. McCormack, "Estimating the Benefits and Risks of Implementing E-Procurement", IEEE Transactions On Engineering Management, vol. 57, no. 2, May 2010.

[18] P.A. Matt and F. Toni, T. Stournaras, "Argumentation-based agents for eProcurement”, $2^{\text {nd }}$ International Conference on Computational Models of Arguments, 2008.

[19] S. Sato, Y. Asahi, “A Daily-level Purchasing Model at an E-commerce Site”, International Journal of Electrical and Computer Engineering, Vol.2, No.6, pp.831-839, 2012.

[20] S. Subramaniam, S.C. Haw, P.K. Hoong, "Bridging XML and Relational Databases: An Effective Mapping Scheme based on Persistent”, International Journal of Electrical and Computer Engineering (IJECE), Vol. 2, No. 2, pp. 239-246, 2012.

[21] Guidelines for compliance to Quality requirements of eProcurement Systems, Report Drafted by Department of Information Technology, Ministry of Communications \& Information Technology, 2011.

[22] http://finmin.nic.in/the_ministry/dept_expenditure/gfrs/

[23] M. Singh, D. Thomson, "eProcurement Model for B2B Exchanges: An Australian Example", 15 $5^{\text {th }}$ Bled Electronic Commerce Conference eReality: Constructing the eEconomy Bled, Slovenia, June 17 - 19, 2002.

[24] K. Vaidya, G. Callender, A.S.M. Sajeev, J. Gao, "Towards a Model for Measuring the Performance of eProcurement Initiatives in the Australian Public Sector: A Balanced Scorecard Approach”, Australian eGovernance Conference, April, 14-15, 2004.

[25] V. Parida, "The Effect of Benefits and Risks On E-procurement Implementation: An Exploratory Study of Swedish and Indian Firms" ACM-Journal International Journal of Information and Communication Technology, Vol.2 Iss. 3, pp. 186-201, 2010.

[26] F. Bof and P. Previtali, "National models of public (e)-procurement in Europe", Journal of e-Government Studies and Best Practices, Article ID 315295, 14 pages, 2010.

[27] M.K. Sharma, K.S. Vaisla, "E-Procurement model in eGovernance framework of Uttarakhand to provide B2B, G2B, and B2G e-commerce application”, Proceedings of the 2nd National Conference on Computing for Nation Development, ISSN - 0973-7529 \& ISBN - 978-81-904526-2-5, pp.711-712, 2008.

[28] R. Eadie, S. Perera, G. Heaney, "Identification Of Key Process Areas In The Production Of An E-Capability Maturity Model For Uk Construction Organisations, Journal of University of Ulster, vol.1, 2010.

[29] X: http://www.capterra.com/procurement-software/

[30] Wang, Hsing-I, "The Planning of the Architeture of a Public E-Procurement Environment under the Cloud - the Case of Taiwan”, The Journal of Global Business Management, Vol.8, No. 2, 2012.

[31] K. Kiroski, M. Gusev and S. Ristov, "IaaS Cloud Model for e-Ordering and e-Invoicing”, Federated Conference on Computer Science and Information Systems, pp. 105-110, 2013.

[32] S. Ojha and I.M. Pandey, "e-Procurement Project in Karnataka: A Case of Public Private Partnership”, Vikalpa, Vol.39, No.4, 2014.

[33] A. Grilo and R.J. Goncalves, "Electronic Public Procurement Of Construction And Public Works: Towards A New Reality”, International Public Procurement Conference, pp.10-11, 2010.

[34] J. Magnusson, A. Nilsson, "Studying the Implications of Cloud-based delivery models on public IT procurement: A switching cost perspective”, Proceedings eChallanges in Stockholm University, 2011.

[35] N.I. Shalle, W. Guyo, I.M. Amuhaya, "Role of E-Procurement Strategy in Enhancing Procurement Performance in State Corporations in Kenya”, International Journal of Science and Research, Vol.2 Iss.11, November 2013.

[36] E.L. Mencia and S. Holthausen, and A. Schulz, and F. Janssen, "Using Data Mining on Linked Open Data for Analyzing E-Procurement Information”, Proceedings of the first DMoLD: Data Mining on Linked Data Workshop at ECML/PKDD, 2013.

[37] E. Manoranjetha, S. Prasanna, "Resource procurement mechanism scheme for cloud Computing”, Elysium Journal of Engineering Research \& Management, Vol.1, Iss.3, 2014.

[38] M. Naldi, "Forecast Uncertainty in Procurement Decisions for Cloud Storage", UKSim-AMSS 16th International Conference on Computer Modelling and Simulation, 2014.

[39] Z. Zhang, R.T.B. Ma, J. Ding, Y. Yang, "ABACUS: An Auction-Based Approach to Cloud Service Differentiation”, IEEE-International Conference on Cloud Engineering , pp.292,301, 2013. 


\section{BIOGRAPHIES OF AUTHORS}

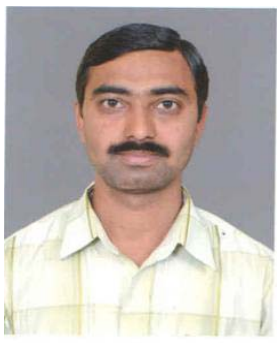

Mr. N. Madhusudan has done Master of Computer Application from Mysore University, India in 1995. He has worked in various reputed Educational Institutions. He has total of 17 years of strong experience in Educational field. Currently he is pursuing his Ph.D from Bharathiar University, Coimbatore, India.

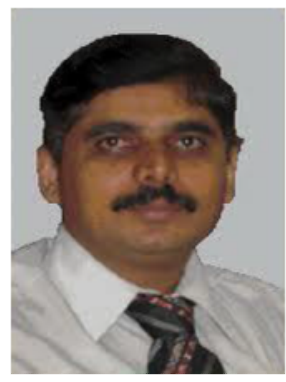

Dr. L. Manjunatha Rao is working as Professor and Head, Department of MCA, Dr.AIT, Bangalore. He has got 25 years of teaching experience. He did his Bachelor of Science from Bangalore University in the year 1990. He Studied Masters of Computer Application from Madhurai Kamaraj University and was awarded in the year 1999. In 2002 did Master of Philosophy from Mononmanium Sundaranar University. He has awarded Ph.D from Vinayaka Mission University, Tamil Nadu. He has published research papers in both national and international Journals and has authored 2 textbooks. 